fully aroused to the frightful evils of vaccination as in no other way. Dr. Gunn also made an address, in which he stated that members of the League held themselves in readiness to prove the fallacy of the theory of vaccination to the satisfaction of the public whenever its advocates or members of the Health Board would discuss it in open debate; and a committee was appointed to draw up articles of incorporation for what is to be known as the "American Anti-Vaccination Society." With the lessons of the Montreal epidemic staring it in the face, the public, for whose welfare these noble gentlemen are so solicitous, is hardly likely to flock to the standard of the new society in overwhelming numbers. It is certainly a bad time to begin an enterprise of this kind at present.

Dr. John T. Nagle, Deputy Register of Records of the Health Department, has given orders to the clerks having charge of the issuing of burial permits not to grant any permits for the removal of bodies from this city to the new Mount Olivet Crematory at Fresh Pond, Long Island, for cremation. The order is based on the fact that the present Sanitary Code makes no provision for the cremation of human bodies, and that this is in reality a violation of the Code. The authorities of the crematory will therefore be obliged to seek legal assistance in rescuing them from the unexpected dilemma in which they are placed.

A very laudable enterprise has just been successfully inaugurated in the opening of a free circulating library for the blind. There are said to be over a thousand blind persons in this city, and as the purchase of raised letter books is necessarily expensive, the library will be an incalculable blessing to many of them who have not the means to buy such works. It is the first project of the kind ever undertaken in this country, and voluntary subscriptions are entirely relied upon for its support.

P. B. P.

REDUCTION OF TEMPERATURE BY ICE-BAGS. To THE Editor of the JoURNal.

Sir:-Stephan, of St. Petersburg (see Journal September $26, \mathrm{I} 885$ ), is of opinion that the temperature in fever may be lowered by the application of ice-bags over the super-clavicular region. This effect is produced by bringing the cold in contact with the large superficial veins of the neck. I have noticed that in some cases of pneumonia a sensation of intense heat is one of the most trying sensations from which the patient suffers. In two of my cases much relief was afforded by the continuous application of the ice-bag to the occipito-cervical region. One of the patients told me "it was the only comfort he had."

$4^{8}$ West 17 th St., New York.

\section{STATE MEDICINE.}

PROVISION FOR THE INSANE IN TENNESSEE.

During the last two years, Tennessee has been actively improving the accommodations for her in- sane. The hospital at Nashville, under the care of the distinguished alienist, Dr. John H. Callender, has been overcrowded for several years. A new asylum at Lyon's View, near Knoxville, in East Tennessee, is nearly completed, and is expected to be open for patients in December next. The site is well selected, and the buildings have been constructed under the direction of Dr. Michael Campbell, who has recently been elected Superintendent of the Institution. Dr. Campbell was with Dr. Callender in the hospital at Nashville iwo years, and is well qualified to fill the place of Superintendent. We learn from a recent copy of the Nashville American, that Dr. C. C. Fite, of that city, has accepted the appointment of Assistant Superintendent in the new asylum at Lyon's View. Dr. Fite is not only well and favorably known to the profession in Tennessee, but throughout the Mississippi Valley, and will discharge the duties of his new position with ability and fidelity. The State has also made an appropriation for another asylum in West Tennessee, and a Commission is now engaged in selecting the most appropriate location.

HEALTH OF MICHIGAN FOR OCTOBER, 1885.

Reports to the State Board of Health, at Lansing, by regular observers in different parts of the State, show that, for the month of October, 1885 , compared with the preceding month, diphtheria had increased, and that diarrhoea, cholera morbus, dysentery and cholera infantum had decreased in prevalence. Compared with the average for the month of October in the seven years from $1879-1885$, remittent fever, intermittent fever, typho-malarial fever, diarrhœa, consumption of the lungs, typhoid fever, bronchitis, dysentery, and cholera morbus, were less prevalent in October, 1885 .

For the month of October, I885, compared with the average of corresponding months for the seven years $1879^{-1} 885$, the temperature was lower, the absolute humidity was less, the relative humidity was much more, and the day and the night ozone were more. Including reports from regular observers and others, diphtheria was reported in fifty-nine places within the State during the month, and measles in three places.

\section{ASSOCIATION ITEMS.}

\section{INFORMA'TION OF IMPORTANCE TO ALL MEMBERS OF THE AMERICAN MEDI- CAL ASSOCIATION.}

Membership.-Every one who attends an annual meeting of the Association as a delegate pays at that time five dollars, and thenceforward becomes a Permanent Member. He continues as such as long as he remains in good standing in the body from which he was originally sent as a delegate. As a Permanent Member, he must pay Five Dollars Annually, when notified by the Treasurer, whether he attends the meetings of the Association or not. Payment of annual dues entitles him to receive the weekly JOURnal of the Association for one year. 